\title{
EFICIÊNCIA DOS DILUIDORES TRIS E BOTU-CRIO® SOBRE OS PARÂMETROS SEMINAIS DE GARANHÕES DAS RAÇAS QUARTO DE MILHA E MANGALARGA MARCHADOR
}

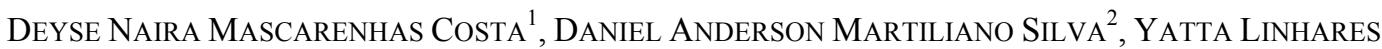 \\ BOAKARI $^{2}$, SILUANA BENVINDO FERREIRA ${ }^{1}$, MARLON ARAÚJO CASTELO BRANCO ${ }^{3}$, JOSÉ AdALMIR \\ TORRES DE SOUZA ${ }^{4}$
}

\footnotetext{
${ }^{1}$ Pós-Graduandas da Universidade Federal do Piauí, Teresina, PI, Brasil. missmascarenhas@hotmail.com

${ }^{2}$ Graduação em Medicina Veterinária, Universidade Federal do Piauí, Teresina, PI, Brasil

${ }^{3}$ Pós-Graduando, Rede Nordeste de Biotecnologia - RENORBIO, Teresina, PI, Brasil

${ }^{4}$ Professor Doutor da Universidade Federal do Piauí, Teresina, PI, Brasil
}

O principal fator a limitar o processo de criopreservação de sêmen equino está relacionado à própria espécie, por apresentar uma grande variabilidade nas características dos ejaculados pós-descongelação. $\mathrm{O}$ objetivo desta pesquisa foi avaliar a viabilidade espermática pósdescongelação, do sêmen de garanhões das raças Quarto de Milha e Mangalarga Marchador utilizando-se dois diluentes (Tris e Botu-crio ${ }^{\circledR}$ ) na criopreservação. Para tanto, foram analisadas as características físicas do sêmen fresco, funcionalidade da membrana espermática pelo Teste Hiposmótico (HOST), motilidade total e vigor pelo Teste de Termoresistência (TTR), motilidade progressiva pelo sistema computadorizado CASA (Computer Assisted Sêmen Anlyses) e integridade da membrana espermática, do acrossoma e funcionalidade de mitocôndria por microscopia de epifluorescência. O diluente Botu-crio ${ }^{\circledR}$ preservou melhor os valores de motilidade e vigor e a integridade de membrana plasmática, pósdescongelamento. Não houve diferença significativa entre as raças quanto à motilidade total e vigor no sêmen fresco, bem como para a análise desses parâmetros no Teste de Termoresistência pós-descongelamento. Garanhões da raça Quarto de Milha apresentaram percentual maior de defeitos maiores na análise de patologia espermática.

PALAVRAS-CHAVE: criopreservação, diluente, equino, sêmen

\section{EFFICIENCY OF TRIS EXTENDERS AND BOTU-CRIO ® ON SEMINAL PARAMETERS IN STALLION BREEDS QUARTER HORSE AND MANGALARGA MARCHADOR}

\section{ABSTRACT}

The limiting factor in the cryopreservation process of equine semen is related to the species, as they present a great variability in the ejaculate's characteristics after thawing. The aim of this study was to evaluate sperm viability after thawing, from Quarter Horse and Mangalarga Marchador stallions using two extenders (Botu-crio and Tris) in cryopreservation. To this end, we analyzed the physical characteristics of fresh semen, the sperm membrane functionality by the hypoosmotic swelling test (HOST), total motility and vigor by the Thermoresistance Test (TRT), progressive motility by a computerized system CASA (Computer-Assisted Semen Anlyses) and acrosomal membrane integrity and functionality of the mitochondria by epifluorescence microscopy. After thawing, the extender Botu-crio $\AA$ better preserved motility, vigor and integrity of the plasma 
membrane. There was no significant difference between breeds for the thermoresistance test after twaing. Quarter

KEYWORDS: cryopreservation, equine, extender, semen.

\section{INTRODUÇÃO}

A criopreservação do sêmen equino tem grande importância no melhoramento genético da espécie por permitir maximizar o uso de bons reprodutores ${ }^{1}$; contudo, o principal entrave para o uso do sêmen criopreservado está relacionado com uma grande variação observada entre indivíduos na habilidade de os espermatozóides sobreviverem ao processo de congelação ${ }^{2}$ e até mesmo entre ejaculados de um mesmo garanhão ${ }^{3}$.

Essa diferença também ocorre entre raças e, dentre as raças brasileiras, as raças Mangalarga Paulista e Mangalarga Marchador são as de menor resistência ao processo de congelação ${ }^{2}$. Alguns autores afirmam que a variabilidade na resistência do espermatozóide ao processo de criopreservação está relacionada a fatores genéticos ${ }^{4}$.

Para equinos, vários diluentes tem sido formulados, a maioria à base de gema de ovo ou leite desnatado ${ }^{5}$. A gema de ovo é o mais eficiente dos crioprotetores não penetrantes na proteção do espermatozóide contra o choque térmico, mas não apresenta a mesma eficiência em todas as espécies ${ }^{6}$.

Estudos realizados por Gomes et al. ${ }^{2}$ demonstraram que crioprotetores à base de amidas proporcionam resultados superiores em relação ao glicerol no que se refere à motilidade espermática, integridade da membrana espermática e integridade de acrossoma, em diferentes raças equinas.

Os principais trabalhos desenvolvidos nas últimas duas décadas contemplam a adoção de técnicas computadorizadas de avaliação do movimento espermático, testes de incubação e separação espermática e análise morfofuncional por meio de sondas fluorescentes para predizer o real potencial de fertilização das amostras de sêmen congelado ${ }^{7,8}$.

A avaliação da motilidade e morfologia é essencial na análise da qualidade do sêmen. A análise desses parâmetros tem sido baseada na avaliação subjetiva, resultando em variações de até $60 \%$ entre diferentes avaliadores. Para reduzir a subjetividade, sistemas computadorizados de análise seminal vem sendo desenvolvidos, fornecendo confiabilidade e velocidade de obtenção dos dados ${ }^{9}$. No entanto, mesmo a avaliação computadorizada do movimento espermático proporciona correlação inconsistente
Horse showed higher percentage of bigger defects in the sperm pathology analysis.

com os índices de concepção quando utilizada isoladamente, visto que a motilidade espermática representa apenas um dos vários pré-requisitos básicos indispensáveis para que os espermatozóides concluam com êxito sua função biológica representada pela fertilização do ovócito $^{10}$. Por isso, deve-se lançar mão de uma combinação de testes laboratoriais para predizer a real qualidade do sêmen analisado, bem como associá-los ao teste in vivo para constatar o potencial de fertilidade de um determinado reprodutor.

O objetivo do presente trabalho foi avaliar o potencial reprodutivo do sêmen criopreservado de garanhões das raças Mangalarga Marchador e Quarto de Milha, utilizando-se como diluentes os meios Tris-gema e Botu-crio ${ }^{\circledR}$ à base de gema de ovo acrescido de amidas.

\section{MATERIAL E MÉTODOS}

Foram utilizados 12 garanhões com idades entre três a cinco anos, sendo seis da raça Quarto de Milha e seis da raça Mangalarga Marchador, pertencentes a dois haras localizados no Município de José de Freitas, Piauí, situado a 04 $45^{\prime} 23^{\prime \prime}$ sul de latitude e $42^{\circ} 34^{\prime} 32^{\prime \prime}$ oeste de longitude, a $138 \mathrm{~m}$ de altitude e com clima caracterizado como tropical úmido. Seis ejaculados por animal foram colhidos com intervalo mínimo de 48 horas entre as colheitas, num total de 72 ejaculados. As colheitas foram por meio de vagina artificial, em copo coletor graduado, para medição do volume seminal e com uma gaze estéril para filtragem do sêmen e descarte da fração gel, preparada com água aquecida a $45^{\circ} \mathrm{C}$; como manequim foi utilizada uma égua em estro.

Imediatamente após a colheita, foram analisados, visualmente, o volume, o aspecto e a cor e, sob microscopia convencional, a motilidade total e o vigor, segundo Manual do Colégio Brasileiro de Reprodução Animal-CBRA ${ }^{11}$. Uma alíquota de $10 \mu \mathrm{L}$ de sêmen de cada ejaculado foi diluída em $1 \mathrm{~mL}$ de citrato de sódio formalizado e transportado para o laboratório, onde determinouse a concentração espermática, utilizando-se a câmara de Neubauer (espermatozóide $/ \mathrm{mL}$ ) e realizou-se a análise morfológica, por meio da técnica da câmara úmida.

Após essas análises, os ejaculados com motilidade mínima de $60 \%$ foram diluidos no meio 
de resfriamento Botu-sêmen ${ }^{\circledR}$ (Biotech Botucatu, Botucatu-SP, Brasil) na proporção de 1:1, perfazendo um total de $10 \mathrm{~mL}$ de solução sêmen:diluidor.

Em seguida, as amostras foram acondicionadas em conteiner (Equitainer ${ }^{\circledR}$ ), a 5 ${ }^{\circ} \mathrm{C}$, e encaminhadas ao Laboratório de Biotecnologia da Reprodução Animal da Universidade Federal do Piauí. No laboratório, as amostras foram centrifugadas a $650 \mathrm{G}$ por 10 minutos, o sobrenadante desprezado e os "pellets" ressuspendidos com os meios de congelação Trisgema (Formulação no laboratório: Trishidroximetil-aminometano, ácido cítrico, frutose, gema de ovo, glicerol) ou Botu-crio ${ }^{\circledR}$ (Biotech Botucatu, Botucatu- SP, Brasil) (gema de ovo, glicerol, metilformamida).

A diluição foi realizada de modo a assegurar uma concentração espermática de 100 milhões de espermatozóides por palheta de 0,5 $\mathrm{mL}$, previamente identificadas. Após o envase, as palhetas foram lacradas e congeladas em máquina automatizada, modelo TK- 3000, em curva específica de congelação para equino, com taxa de resfriamento lento $\left(-0,33{ }^{\circ} \mathrm{C} /\right.$ minuto $)$.

Duas semanas após a congelação, uma palheta de cada ejaculado foi descongelada em Banho-Maria a $37^{\circ} \mathrm{C}$ por 20 segundos e o sêmen avaliado quanto à motilidade e o vigor, nos tempos $0,60,120$ e 180 minutos (Teste de Termoresistência).

De cada amostra descongelada, foi retirada uma alíquota de $10 \mu \mathrm{L}$ destinada à realização do Teste Hiposmótico (HOST) para avaliação da integridade funcional da membrana plasmática. Outra alíquota de $10 \mu \mathrm{L}$ foi destinada à análise da integridade da membrana plasmática, além da integridade do acrossoma e a funcionalidade mitocondrial por meio de sondas fluorescentes, segundo metodologia descrita por Celeghini et al. ${ }^{12}$.

Uma palheta de cada ejaculado foi destinada à análise computadorizada (CASAComputer Assisted Sêmen Anlyses) das características seminais. Uma alíquota de $10 \mu \mathrm{L}$ foi colocada na câmara de Makler pré-aquecida e analisada em computador acoplado a um microscópio equipado com um adaptador para câmara de vídeo com lentes de 40 a 100 vezes de aumento.

Para comparação, entre raças, das características físicas e morfológicas dos ejaculados, utilizou-se o delineamento inteiramente casualizado com seis repetições (6 animais).

$\mathrm{Na}$ análise do sêmen pós-descongelação, utilizou-se o modelo estatístico fatorial $2 \times 2$ (duas raças e dois diluentes) com seis repetições. Para as médias, foi realizado o teste SNK de comparação a $5 \%$ de probabilidade.

O presente trabalho foi submetido ao Comitê de Ética em Experimentação com Animais - CEEA/UFPI e teve parecer aprovado sob o $\mathrm{n}^{\circ}$. $069 / 12$.

\section{RESULTADOS E DISCUSSÃO}

Não se observou diferença significativa quanto às características seminais entre as raças (Tabela 1). O volume dos ejaculados relativamente baixo pode estar relacionado ao fato de os garanhões estarem em atividade reprodutiva e em regime de treinamento para competições esportivas, como também ao período em que o trabalho foi executado (outubro/dezembro), quando as temperaturas são mais elevadas, gerando mais desconforto aos animais, muito embora as colheitas tenham sido realizadas no mínimo 48 horas após as competições.

Os valores médios para o vigor apresentaram-se abaixo do preconizado pelo CBRA $^{11}$, para fins de congelação e comercialização do sêmen (ideal $\geq 3$ ); entretanto, os ejaculados foram criopreservados de forma satisfatória. A motilidade total apresentou médias satisfatórias para ambas as raças $(\geq 50 \%)$. O mesmo foi verificado para a concentração espermática.

Tabela 1- Médias e desvios-padrão das características do sêmen fresco de garanhões das raças Quarto de Milha e Mangalarga Marchador

\begin{tabular}{lcccc}
\hline Raças & $\begin{array}{c}\text { Volume } \\
(\mathrm{mL})\end{array}$ & $\begin{array}{c}\text { Motilidade } \\
(\%)\end{array}$ & $\begin{array}{c}\text { Vigor } \\
(0-5)\end{array}$ & $\begin{array}{c}\text { Concentração } \\
\left(\mathrm{x} 10^{6} / \mathrm{mL}\right)\end{array}$ \\
\hline Quarto de Milha & $23,33 \pm 2,25 \mathrm{a}$ & $67,5 \pm 0,91^{\mathrm{a}}$ & $2,87 \pm 0,05 \mathrm{a}$ & $3,3 \pm 5,48 \mathrm{a}$ \\
Mangalarga Marchador & $24,16 \pm 2,47 \mathrm{a}$ & $62,9 \pm 6,78^{\mathrm{a}}$ & $2,58 \pm 0,32 \mathrm{a}$ & $2,4 \pm 2,77 \mathrm{a}$ \\
\hline
\end{tabular}

Médias seguidas por letras minúsculas iguais na mesma coluna não diferem entre si $(\mathrm{P}<0,05)$. 
De acordo com estudos de Gomes e Gomes ${ }^{1}$, existem diferenças individuais, relativas às características seminais que poderão refletir na fertilidade, utilizando-se sêmen resfriado ou congelado.

O CBRA ${ }^{11}$ preconiza que o sêmen da espécie equina, para ser comercializado, não deve apresentar defeitos totais superiores a $30 \%$, o que está consonante comos dados obtidos neste trabalho.

$\mathrm{Na}$ raça Quarto de Milha, a média de defeitos maiores foi significativamente superior, fator que pode estar relacionado às atividades esportivas intensas e ao manejo nutricional diferenciado em relação ao Mangalarga Marchador (Tabela 2).

Tabela 2 - Médias e desvios-padrão de patologias espermáticas do sêmen fresco de garanhões das raças Quarto de Milha e Mangalarga Marchador

\begin{tabular}{lccc}
\hline \multicolumn{1}{c}{ Raças } & Defeito Maior (\%) & Defeito Menor (\%) & Defeitos Totais(\%) \\
\hline Quarto de Milha & $6,05 \pm 0,52 \mathrm{a}$ & $18,51 \pm 1,43 \mathrm{a}$ & $25,86 \pm 1,54 \mathrm{a}$ \\
Mangalarga Marchador & $3,64 \pm 0,68 \mathrm{~b}$ & $22,04 \pm 4,60 \mathrm{a}$ & $30,35 \pm 3,67 \mathrm{a}$
\end{tabular}

Médias seguidas por letras minúsculas iguais na mesma coluna não diferem entre si $(\mathrm{P}<0,05)$.

Em sêmen de cavalos da raça Pantaneiro foram observados índices baixos de patologias espermáticas totais $(23,31 \pm 0,24)$, o que foi atribuído à seleção natural pela qual os cavalos passaram ${ }^{13}$. No presente estudo, verificou-se que os valores de defeitos totais da raça Quarto de Milha foram próximos aos encontrados por Ribas ${ }^{13}$, sugerindo que, pelo menos sobre as patologias, as condições ambientais não exerceram grandes influências.
Em relação à motilidade, observou-se (Tabela 3; Figura 1) efeito dos tratamentos sobre as raças com o diluidor à base de gema de ovo e meltilformamida, proporcionando melhor valor aos ejaculados dos garanhões da raça Mangalarga Marchador em comparação com a raça Quarto de Milha. Não houve diferença significativa $(P>0,05)$ entre os valores de motilidade referentes ao Tris nas raças.

Tabela 3 - Motilidade total e vigor espermáticos, pós-descongelação, do sêmen de garanhões das raças Quarto de Milha e Mangalarga Marchador, segundo o tipo de diluidor

\begin{tabular}{ccccc}
\hline Raça & \multicolumn{2}{c}{ Motilidade (\%) } & \multicolumn{2}{c}{ Vigor $(0-5)$} \\
\hline & Botu-crio ${ }^{\circledR}$ & Tris & Botu-crio ${ }^{\circledR}$ & Tris \\
Quarto de Milha & $19,59 \pm 10,34^{\text {a }}$ & $15,21 \pm 8,75^{\text {a A }}$ & $1,85 \pm 1,11^{\text {a }}$ & $1,47 \pm 0,75^{\text {a A }}$ \\
Mangalarga Marchador & $30,67 \pm 13,52^{\text {a A }}$ & $17,26 \pm 11,40^{\text {b A }}$ & $2,48 \pm 0,73^{\text {a }}$ & $1,62 \pm 0,96^{\text {b A }}$ \\
\hline
\end{tabular}

Médias seguidas por letras minúsculas iguais na mesma linha não diferem entre si $(\mathrm{P}<0,05)$.

Médias seguidas por letras maiúsculas iguais na mesma coluna não diferem entre si $(\mathrm{P}<0,05)$.

Em relação ao vigor (Tabela 3; Figura 2), o diluidor à base de amidas preservou melhor o resultado em ambas as raças, comparado com o diluidor Tris, havendo, assim, diferença significativa entre os diluentes $(\mathrm{P}<0,05)$. Garanhões da raça Mangalarga Marchador apresentaram vigor maior no sêmen diluído com diluidor contendo metilformamida e Tris. 


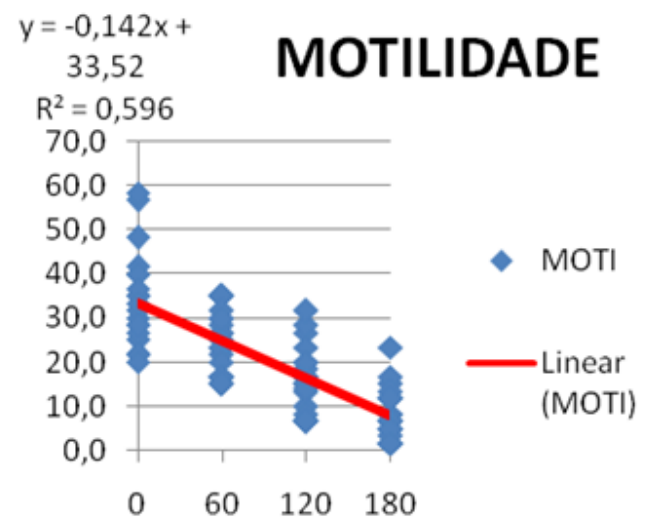

Figura1- Médias de motilidade espermática de garanhões submetidos ao teste TTR, nos tempos $0,60,120$ e 180 minutos.

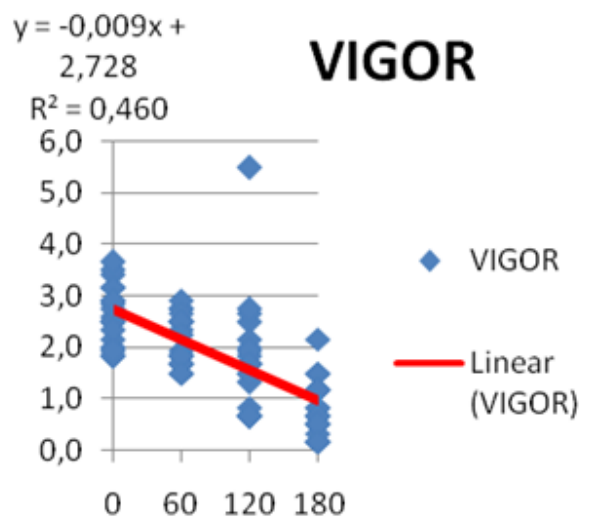

Figura 2- Médias de vigor espermático de garanhões submetidos ao teste TTR, nos tempos $0,60,120$ e 180 minutos.
Os resultados verificados no TTR diferem dos obtidos por Silva et al. ${ }^{14}$ quando, ao compararem o efeito de diferentes diluentes à base de gema de ovo sobre a viabilidade do sêmen pósdescongelamento, observaram que os parâmetros motilidade total, motilidade progressiva e vigor espermático não apresentaram diferenças significativas $(\mathrm{P}>0,05)$ aos 60 minutos de incubação. Entretanto, a partir do tempo 120 minutos, verificaram diferenças $(\mathrm{P}<0,05)$ na motilidade total e no vigor espermático.

$\mathrm{Na}$ avaliação da integridade da membrana plasmática não houve interação entre raças e diluentes $(\mathrm{P}<0,05)$, de modo que, entre as raças, esse valor foi maior nos animais Quarto de Milha e as amostras de sêmen diluídas com o diluente à base de amidas apresentaram maior número de espermatozóides com membrana intacta, como demonstrado nas Tabelas 4 e 5.

Nas análises da membrana acrossomal, potencial de mitocôndria e o Teste Hiposmótico (HOST), apresentadas nas Tabelas 4 e 5, não houve interação entre os diluentes e as raças $(\mathrm{P}>0,05)$. A raça Quarto de Milha apresentou funcionalidade maior das mitocôndrias e o HOST apresentou maior percentagem de formas reativas. Já a funcionalidade da membrana acrossomal não apresentou diferença dos percentuais de acrossoma intacto entre as raças.

O diluente Tris apresentou menor número de espermatozóides com membrana intacta e maior percentual de acrossomas intactos.

Os valores obtidos para integridade da membrana corroboram com os dados de Furst et al. ${ }^{15}$ que, ao avaliarem o resfriamento de sêmen equino prévio ao congelamento, encontraram uma taxa de $71 \%$ de integridade de membrana em diluentes à base de gema de ovo associados ao crioprotetor metilformamida. Resultados similares foram também encontrados por Terraciano et al. ${ }^{16}$ que, ao compararem amostras de ejaculados diluídas em Botu-crio e em FR-5, constataram que as amostras diluídas com Botu-crio apresentaram melhores taxas de preservação da integridade da membrana plasmática após o descongelamento.

Tabela 4- Médias e desvios-padrão da integridade de membrana plasmática (\%), integridade de acrossoma (\%), potencial da membrana mitocondrial (\%), integridade funcional da membrana plasmática (HOST, \%) de espermatozóide equino das raças Quarto de Milha e Mangalarga Marchador

\begin{tabular}{lcc}
\hline \multicolumn{1}{c}{ Estruturas } & \multicolumn{2}{c}{ Raça } \\
\cline { 2 - 3 } & Quarto de Milha & Mangalarga Marchador \\
\hline Membrana Plasmática & $55,12 \pm 2,27^{\mathrm{a}}$ & $47,58 \pm 2,93^{\mathrm{b}}$ \\
Acrossoma & $9,75 \pm 2,56^{\mathrm{a}}$ & $14,83 \pm 3,68^{\mathrm{a}}$ \\
Mitocondria & $78,08 \pm 2,48^{\mathrm{a}}$ & $58,45 \pm 2,47^{\mathrm{b}}$ \\
HOST & $17,79 \pm 1,86^{\mathrm{a}}$ & $12,00 \pm 1,69^{\mathrm{b}}$ \\
\hline
\end{tabular}

Médias seguidas por letras minúsculas iguais na mesma linha não diferem entre si $(\mathrm{P}<0,05)$. 
Tabela 5- Médias e desvios-padrão da integridade de membrana plasmática (\%), integridade de acrossoma (\%), potencial da membrana mitocondrial (\%), integridade funcional da membrana plasmática (HOST,\%) de espermatozóide de garanhões das raças Quarto de Milha e Mangalarga Marchador

\begin{tabular}{lcc}
\hline Estruturas & \multicolumn{2}{c}{ Diluentes } \\
\cline { 2 - 3 } & Botu-crio ${ }^{\circledR}$ & Tris \\
\hline Membrana Plasmática & $58,00 \pm 1,47^{\mathrm{a}}$ & $44,70 \pm 1,47^{\mathrm{b}}$ \\
Acrossoma & $5,66 \pm 3,46^{\mathrm{b}}$ & $18,91 \pm 1,14^{\mathrm{a}}$ \\
Mitocondria & $68,16 \pm 3,67^{\mathrm{a}}$ & $68,35 \pm 4,03^{\mathrm{a}}$ \\
HOST & $16,75 \pm 2,16^{\mathrm{a}}$ & $13,04 \pm 1,60^{\mathrm{a}}$ \\
\hline
\end{tabular}

Médias seguidas por letras minúsculas iguais na mesma linha não diferem entre si $(\mathrm{P}<0,05)$.

Em relação ao potencial de membrana mitocondrial, o presente trabalho constatou valores que estão de acordo com os achados por Oliveira et al. ${ }^{17}$, que não verificaram diferenças significativas entre os diluidores à base de amidas e EDTALACTOSE.

Estudos realizados por Landim-Alvarenga ${ }^{18,}$ em relação à preservação da integridade do acrossoma, demonstraram que os crioprotetores à base de amidas, principalmente dimetilformamida e metilformamida, foram mais eficientes em preservar a integridade acrossomal pós-descongelamento em relação ao glicerol. Tal fato não foi evidenciado neste estudo, em que o diluidor com metilformamida apresentou menor percentual de integridade de membrana acrossomal do que o diluidor Tris.

Em relação ao Teste Hiposmótico, não foi evidenciada diferença significativa para os diluentes, sendo significativo só entre as raças. Tal constatação não condiz com os resultados obtidos por Terraciano et al. $^{16}$, que evidenciaram eficiência superior para funcionalidade da membrana, na criopreservação de espermatozóides diluídos com diluidor à base de dimetilformamida. Os resultados obtidos para esse parâmetro (HOST) evidenciaram que a eficiência da regulação osmótica pode estar relacionada com a composição celular. Segundo Alvarenga e $\mathrm{Papa}^{4}$, devem existir componentes na membrana plasmática dos indivíduos tidos como de boa congelabilidade, que conferem uma melhor adaptação a meios de diferentes osmolaridade. A eficiência dos diluidores contendo amidas pode estar relacionada ao seu baixo peso molecular, permitindo maior penetrabilidade através das membrana plasmática e acrossomal, proporcionando menor dano osmótico ${ }^{6}$.

Os dados de motilidade progressiva obtidos (Tabela 6) demonstram que houve uma interação significativa entre as raças e os diluentes; com isso, os ejaculados diluídos com diluidor contendo metilformamida apresentaram valores de motilidade superiores ao Tris e, dentre as raças, a Mangalarga Marchador apresentou valores mais satisfatórios com a utilização deste diluente.

Tabela 6- Médias e desvios-padrão referentes à motilidade progressiva e a frequência de batimentos flagelares cruzados (BCF) de espermatozóides de garanhões das raças Quarto de Milha e Mangalarga Marchador avaliados pelo sistema computadorizado (CASA)

\begin{tabular}{lcccc}
\hline Raça & \multicolumn{3}{l}{ Motilidade $(\%)$} & \multicolumn{2}{l}{ Botu-crio ${ }^{\circledR}$} & \multicolumn{1}{c}{ Tris } \\
\cline { 2 - 5 } & Botu-crio ${ }^{\circledR}$ & Tris & $8,58 \pm 0,26^{\mathrm{bA}}$ & $9,06 \pm 0,84^{\mathrm{Aa}}$ \\
\hline Quarto de Milha & $16,39 \pm 40,84^{\mathrm{Ba}}$ & $5,87 \pm 3,64^{\mathrm{Ab}}$ & $8,42 \pm 3,12^{\mathrm{aA}}$ & $7,26 \pm 2,01^{\mathrm{Bb}}$ \\
\hline Mangalarga Marchador & $39,97 \pm 55,41^{\mathrm{Aa}}$ & $7,97 \pm 18,00^{\mathrm{Ab}}$ & 8 & \\
\hline
\end{tabular}

Médias seguidas por letras minúsculas iguais na mesma linha não diferem entre si $(\mathrm{P}<0,05)$.

Médias seguidas por letras maiúsculas iguais na mesma coluna não diferem entre si $(\mathrm{P}<0,05)$.

Os valores encontrados para motilidade progressiva avaliada pelo sistema computadorizado indicam que amostras criopreservadas com diluente à base de amidas apresentam melhores resultados de motilidade progressiva pós-descongelamento, o que também foi verificado por Terraciano et al. ${ }^{16}$. Tal 
fato é justificado por Gomes et al. ${ }^{2}$ e Oliveira et al. ${ }^{19}$, ao afirmarem que diluentes contendo amidas em sua formulação produzem melhores resultados em relação a sêmens que foram congelados com diluidores contendo alta concentração ou somente glicerol como crioprotetor. Essa diferença entre a ação dos diluentes pode estar relacionada à melhor permeabilidade das aminas na célula espermática, acarretando injúrias menores ${ }^{4}$.

Ao analisar os parâmetros de motilidade progressiva e motilidade total pelo sistema CASA, relacionando diluentes com dimetilfomamida a $5 \%$ e glicerol a 5\%, utilizando-se 55 garanhões, Alvarenga et al. $^{20}$ encontraram valores superiores para esses parâmetros com diluentes que possuem dimeltilformamida na composição, estando de acordo com os valores encontrados no presente trabalho.

$\mathrm{Na}$ frequência de batimento flagelar cruzado (BCF), observou-se interação significativa entre diluidores e raças, sendo que o número de batimentos cruzados da cauda do espermatozóide foi semelhante entre as raças para o diluidor contendo metilformamida; no entanto, isso não foi observado para o diluente Tris, que apresentou um maior número de batimentos na raça Quarto de Milha, o que pode influenciar a trajetória do espermatozóide e seu movimento.

$\mathrm{Na}$ análise dos parâmetros de velocidade curvilínea (VCL), velocidade linear progressiva (VSL), velocidade média da trajetória (VAP), linearidade (LIN), retilinearidade (STR), WOB (Tabela 7), somente os diluentes foram significativos, havendo diferença entre os diluidores contendo amidas e Tris: o primeiro apresentou todos os parâmetros superiores ao segundo. Já para ALH (amplitude do deslocamento lateral da cabeça), não foi verificada diferença significativa entre os tratamentos.

Tabela.7- Médias e desvios-padrão referentes aos parâmetros VCL, VSL, VAP, LIN, STR, WOB analisados pelo sistema computadorizado (CASA), no sêmen de garanhões Quarto de Milha e Mangalarga Marchador, segundo o tipo de diluente

\begin{tabular}{lcccccc}
\hline \multirow{2}{*}{ Diluente } & \multicolumn{5}{c}{ Parâmetros } \\
\cline { 2 - 6 } & VLC & VSL & VAP & LIN & SRT & WOB \\
\hline Botu-crio & $42,61 \pm 2,34^{\mathrm{a}}$ & $32,07 \pm 2,78^{\mathrm{a}}$ & $38,83 \pm 3,24^{\mathrm{a}}$ & $62,06 \pm 1,98^{\mathrm{a}}$ & $81,73 \pm 1,04^{\mathrm{a}}$ & $71,52 \pm 2,18^{\mathrm{a}}$ \\
\multirow{2}{*}{ Tris } & $29,01 \pm 2,91^{\mathrm{b}}$ & $14,48 \pm 1,47^{\mathrm{b}}$ & $18,52 \pm 1,89^{\mathrm{b}}$ & $40,24 \pm 4,47^{\mathrm{b}}$ & $63,49 \pm 9,26^{\mathrm{b}}$ & $54,66 \pm 3,93^{\mathrm{b}}$ \\
\hline
\end{tabular}

Médias seguidas de letras minúsculas iguais na mesma coluna não diferem entre si $(\mathrm{P}<0,05)$.

Os valores de padrões de velocidade espermática avaliados pelo CASA, obtidos no presente experimento, são similares aos resultados encontrados por Oliveira et al. ${ }^{19}$ que, nos seus grupos de estudo, não verificaram diferenças significativas entre os padrões. Medeiros ${ }^{7}$ também não encontrou diferenças significativas quando avaliou diluentes com os crioprotetores metilformamida e glicerol.

Em estudo com diluidores EDTALACTOSE e INRA-82, Oliveira et al. ${ }^{17}$ e Vidament et al. $^{21}$ obtiveram resultados similares para os parâmetros VAP, VSL, STR e LIN, não encontrando diferença significativa. Já Gomes et al. ${ }^{2}$ demonstraram que houve melhorias nos parâmetros de motilidade computadorizada (CASA) e integridade da membrana em sêmen de garanhões Mangalarga Marchador congelados com diluidores contendo crioprotetor à base de amidas em relação a amostras congeladas com glicerol.

\section{CONCLUSÃO}

Os resultados demonstram que o uso de diluidor contendo amidas (Botu-crio $\left.{ }^{\circledR}\right)$ como crioprotetores, minimizam os danos osmóticos nas células espermáticas durante $\mathrm{o}$ processo de criopreservação promovendo melhores valores de motilidade total, motilidade progressiva, vigor e integridade de membrana espermática pós descongelamento.

\section{REFERÊNCIAS}

1 Gomes GM, Gomes LPM. Problemas e soluções com o uso de sêmen congelado e refrigerado de garanhões da raça Mangalarga Marchador. Revista Brasileira de Reprodução Animal. 2009; Suppl.6: 210-215.

2 Gomes GM, Jacob JCF, Medeiros ASL, Papa FO, 
Alvarenga MA. Improvement of stallion spermatozoa preservation with alternative cryoprotectants for Mangalarga Marchador breed. Theriogenology. 2002; 58: 277-279.

3 Fagundes BT, Maurício FV, Silva JFS, Shimoya A, Barreto MAP, Ferreira VM. Adição de insulina ao meio crioprotetor seminal de garanhões Mangalarga Marchador. Revista Brasileira de Zootecnia. 2010; 39(2): 273-278.

4 Alvarenga MA, Papa FO. Principais avanços no processamento e aplicação do sêmen congelado de equinos. Spermova. 2011;1 Suppl.1:7-10.

5 Barros LO, Silva, SV, Almeida FC, Silva ECB, Guerra MMP. Efeito da adição de glutationa peroxidase e cisteína ao diluidor de congelação do sêmen equino. Arquivo Brasileiro de Medicina Veterinária e Zootecnia. 2013; 65: 430-438.

6 Medeiros ASL. Amides as cryoprotectants for freezing stallion semen: a review. Animal Reproduction Science. 2005; 89: 105-113.

7 Crespilho AM. Efeito do meio diluidor e da dose inseminante sobre a congelabilidade e fertilidade do sêmen bovino utilizado em programas de inseminação artificial em tempo-fixo (IATF). [dissertação]. Botucatu: Universidade Estadual Paulista; 2007. Disponível em http://www.athena.biblioteca.unesp.br/exlibris/bd/bbo/330 04064022P3/2007/crespilho am me botfmvz.pdf

8 Freitas-dell'aqua CP, Crespilho AM, Papa FO, Dell'aqua junior JA. Metodologia de avaliação laboratorial do sêmen congelado bovino. Revista Brasileira de Reprodução Animal. 2009; 33(4): 213-222.

9 Matos DL, Araújo AA, Roberto IG, Toniolli R. Análise computarizada de espermatozóides: revisão de literatura. Revista Brasileira de Reprodução Animal. 2008; 32 (4): 225-232.

10 Graham JK, Mocé E. Fertility evaluation of frozen/thawed semen. Theriogenology. 2005; 64: 492504.

11 Colégio Brasileiro de Reprodução Animal. Manual para exame andrológico e avaliação de sêmen de animal, 3ed. Belo Horizonte: CBRA; 2013.

12 Celeghini ECC, Nascimento J, Raphael CF, Andrade AFC, Arruda RP. Simultaneous assessment of plasmatic, acrosomal, and mitochondrial membranes in ram sperm by fluorescent probes. Arquivo Brasileiro de Medicina Veterinária e Zootecnia. 2010; 62: 536-543.
13 Ribas JAS, Silva JFS, Cunha ICN, Quirino CR. Variação sazonal das características seminais em cavalos Pantaneiros. In: XVII Congresso Brasileiro de Reprodução Animal. Anais do XVII Congresso Brasileiro de Reprodução Animal. Belo Horizonte: Colégio Brasileiro de Reprodução Animal. 2007:61. Acesso em 15 de agosto de 2014. Online. Disponível em: http://www.cbra.org.br/portal/publicacoes/anaisxviicbra/A NAIS $\% 20 d 0 \% 20 X V I I \% 20 C B R A . p d f$

14 Silva KMG, Moraes TAP, Silva ECB. Efeito da adição de trolox e pentoxifilina na motilidade, integridade do acrossoma e do DNA de espermatozóides equinos após descongelação. Arquivo Brasileiro de Medicina Veterinária e Zootecnia. 2009; 61 (1): 42-49.

15 Furst R, Carvalho GR, Furst MCO, Ruas JRM, Borges AM, Mafilli V. Efeito do resfriamento do semên equino sobre sua congelabilidade. Arquivo Brasileiro de Medicina Veterinária e Zootecnia. 2005; 57: 599-607.

16 Terraciano PB, Bustamante-filho IC, Miquelito LV, Arlas T R, Castro F, Mattos RC, Passos EP, Oberst ER, Lima EOC. Criopreservação de espermatozóides equinos comparando duas curvas de congelamento combinadas com diluentes comerciais: uma análise laboratorial. Ciência Rural. 2008; 38 (7): 1972-1977.

17 Oliveira GC, Oliveira BMM, Celeghini ECC, Fernandes $\mathrm{CB}$, Mattos CB. Criopreservação do sêmen equino: uma revisão. Revista Brasileira Reprodução Animal. 2013; 37(1): 23-28.

18 Landim-alvarenga MA, Landim-alvarenga FC, Papa FO, Medeiros ASL. Amides as cryoprtectants for freezing stallion semen. Animal Reproduction Science. 2005; 89: 105-113.

19 Oliveira RA, Rubins MIB, Silva CAM. Índice de prenhez com sêmen congelado de garanhões da raça crioula usando glicerol ou dimetilformamida como crioprotetores. Ciência Animal Brasileira. 2013; 14(4): 488-494.

20 Alvarenga MA. Melhoria da resistência espermática ao congelamento e diminuição das variações entre raças e indivíduos com o uso da dimetilformamida para sêmen de garanhões. [Tese]. Botucatu: Universidade Estadual Paulista; 2003.

21 Vidament M, Vicent P, Yvon JM, Martin FX. Glicerol in semen extender is limiting factor in the fertility in asine and equine species. Animal Reproduction Science. 2005; 89 (1-4): 105-113. 